\title{
TECHNO-ECONOMIC FEASIBILITY STUDY OF BIOETHANOL PRODUCTION FROM A COMBINED CELLULOSE AND SUGAR FEEDSTOCK IN NIGERIA: 2-ECONOMIC ANALYSIS
}

\author{
T. Oyegoke ${ }^{1, *}$ and F. Dabai ${ }^{2}$ \\ 1,2, Chemical Engineering Dept., FaCulty of EngR., Ahmadu Bello University Zaria, Kaduna State, NiGERIA. \\ E-mail addresses:1'oyegoketoyese@gmail.com,2fndabai@abu.edu.ng
}

\begin{abstract}
The use of bioethanol in internal combustion engines is a potential green alternative to fossil fuel. Therefore, there is a need to encourage private and government investments in bioethanol production. Here, the techno-economic feasibility of establishing a 148 million liters/annum sugarcane-based bioethanol plant in Nigeria has been studied in order to motivate investors. It was undertaken with the aid of computational software (MATLAB R2017a and Excel 2016). The study shows that the plant will yield a benefit/cost ratio, net present worth, payback period and return on investment value(s) of $1.46, \$ 4.29$ million, 10 years and $8 \%$ respectively, which suggests that the proposed plant would be economically feasible and profitable in Nigeria, based on the conditions adopted for the study.
\end{abstract}

Keywords: Economic, Feasibility, Biofuel, Bioethanol, Cellulose, Sugar

\section{INTRODUCTION}

Nigeria is well-known for its exportation of crude oils and importation of refined oils, in which gasoline is the main imported product. Its dependence on this limited fossil fuel has negative impact(s) on the environment as well as the economy. In particular, the over-reliance of the Nigeria economy on petroleum resources means that when there is a fall in crude oil price, which has become frequent, as shown on Figure 1, its annual revenue is largely affected. In addition, fossil fuels have negative impact on the environment. In consideration of these triple challenges-over dependence on imported products, fluctuating fuel prices and

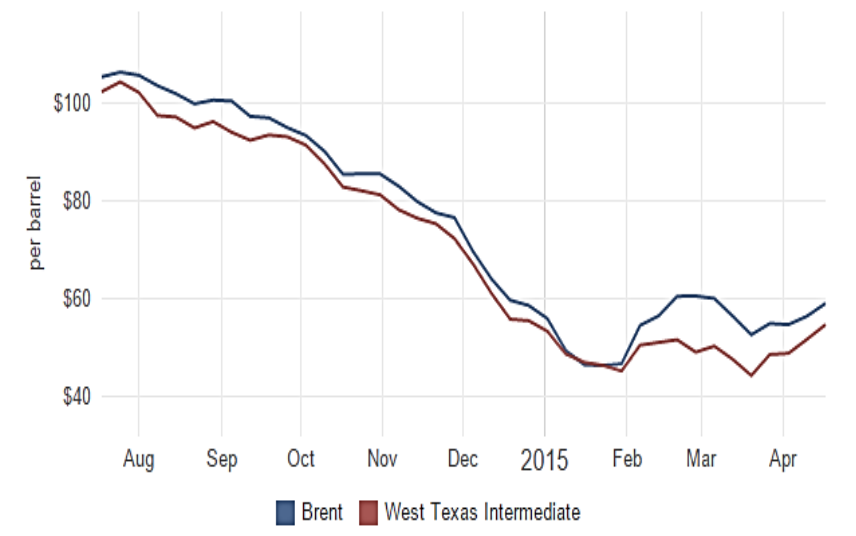

environmental pollution - in 2010, the Nigeria government mandated that all imported gasoline must be blended with $10 \%$ bioethanol to give E10 blend [1], thereby promoting bioethanol, as well as biodiesel and biogas productions. This is a step in the right direction, since the use of biomass and other renewable energy has been suggested [2] as one of the solutions to the problem of environmental issues, which include global warming, climate change, emergence of drought, spread of diseases and variation in population sizes of both plant and animal species [3, 4].

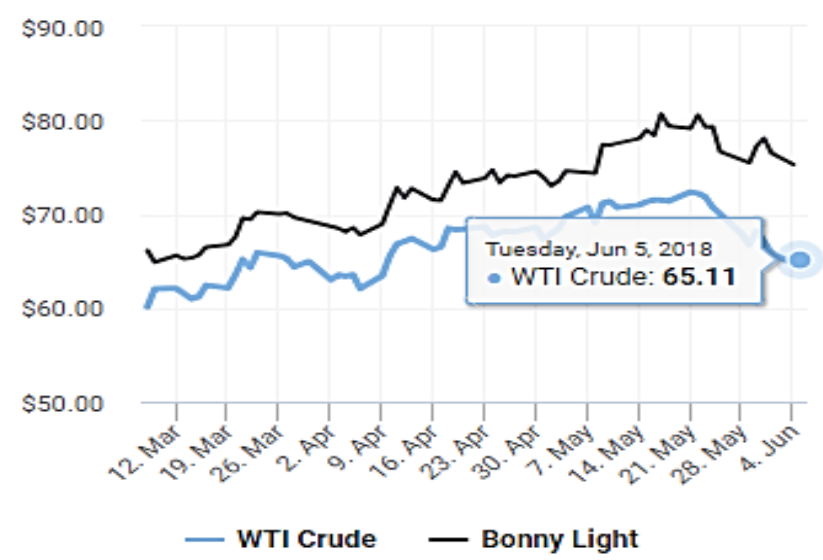

Figure 1: WTI-Brent [8] and WTI-Bonny [9] Crude Oil Price.

\footnotetext{
* Corresponding author, tel: +234-809-867-9625
} 


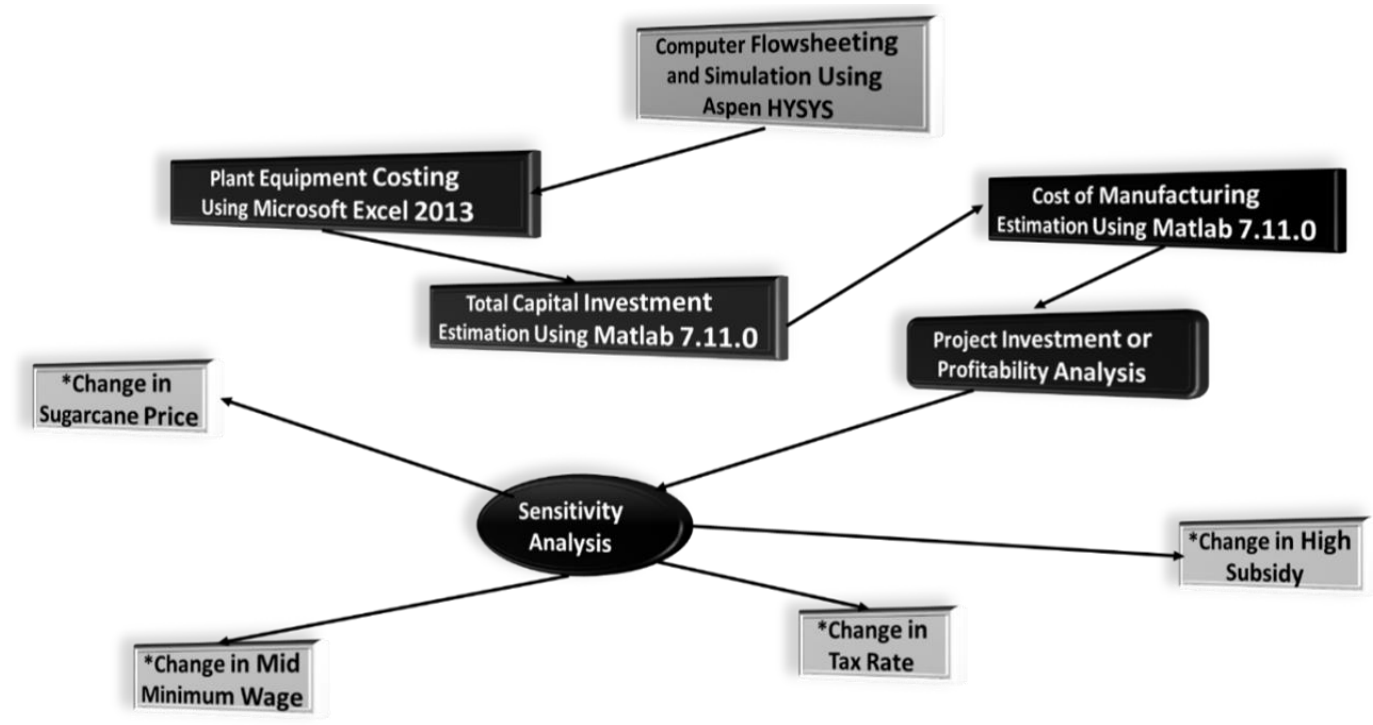

Figure 2: Flow Chart for Process Techno-economic Analysis

In particular, bioethanol is an attractive alternative to gasoline $[5,6]$ as it is derived from renewable sources and it has $35 \%$ oxygen content, which promotes fuel combustion and reduces harmful tail-pipe emissions that pose a health hazard [7]. Economic feasibility studies, such as that carried out for bioethanol production from sugarcane and/or molasses for plants located in Kanchanaburi and Khonkaen province (in Thailand) with a production capacity of 150,000 L/day established feasible condition(s) [10]. The study suggested a fixed investment cost of 1,136 Mbaht for the production of bioethanol from sugarcane and molasses and 745 Mbaht for the production of bioethanol from molasses. Although the benefits of bioethanol production, which include environmental benefits, are well known in Nigeria, there are no categorical conclusions on the economic feasibility of large-scale bioethanol production in Nigeria. This may be responsible for the low level of investments in biofuels production in Nigeria. Therefore, in this study, the techno-economic viability of establishing a bioethanol plant in Nigeria under the current economic environment was undertaken. The research examines economic viability as well as the sensitivity of some selected variables to the viability of establishing a bioethanol plant, using sugarcane juice and bagasse, in Nigeria. The study was carried out with the aid of computational software (MATLAB R2017a).

\section{MATERIALS AND METHODS}

\subsection{Process Descriptions}

The process considered (where crushed sugarcane, composed of sugarcane juice and bagasse, is converted into bioethanol fuel) in this study is described in the earlier study [11], where modelling, simulation and cost evaluation was carried out.

\subsection{Techno-economic Analysis for Bioethanol Production}

To evaluate the profitability of establishing a bioethanol plant in Nigeria, the proposed model and simulated process technology was subjected to economic assessment(s), using different economic cases, with the aid of MATLAB R2017a and Excel 2016, as illustrated in Figure 2.

Based on an earlier study [11], a total capital investment of $\$ 51$ million $(0.34 \quad \$ / L)$ and a manufacturing cost of $\$ 89$ million $(0.61 \$ / \mathrm{L})$ were adopted. The relevant parameters employed in this study are presented in Table 2 .

Table 2: Project Parameters and Assumptions

\begin{tabular}{ll}
\hline Parameters & Values \\
\hline Working time & 24 hours/day, for 335 days/year \\
Raw material (1) & Sugarcane $50,000 \mathrm{~kg} /$ hour for $27 \mathrm{~A} / \mathrm{kg}$ \\
Discount rate & $10.00 \%$ \\
Working capital rate (2) & $5.00 \%$ per year \\
Proposed product price & $0.50-0.67$ \$/L (100-133 A/L) \\
Exchange rate & $360 \mathrm{~N} / \$$ \\
Tax rate / Interest rate & $20.00 / 10.00 \%$ per year \\
Economic life of project & 25.00 years \\
Depreciation method (3) & Straight Line \\
Depreciation period & 10 years \\
Profit & $6 \%$ \\
\hline \multicolumn{2}{c}{ Adopted: ${ }^{1}[12],{ }^{2}[13], 3[14]}$.
\end{tabular}

\subsection{Profitability Analysis}

The profitability of the proposed project was analyzed with a MATLAB algorithm, using the investment criteria such as: Return on Investment (ROI) [14], Net 
Present Worth (NPW) [15, 14], Payback Period (PBP) [14], Benefit/Cost Ratio (B/C) [16], and Internal Rate of Return (IRR) [15, 14] with the equations (1-4).

$$
\begin{gathered}
R O I=\frac{N P}{T C I} \times 100 \% \\
N P W=\sum\left[\frac{B_{n}-C_{t}}{(1+r)^{t}}\right] \\
\frac{B}{F}=\frac{\left[\sum(P C F)\right]}{\left[\sum(N C F)\right]} \\
\sum\left[\frac{B_{n}-C_{t}}{(1+I R R)^{t}}\right]=0
\end{gathered}
$$

Where, $B$ is the Benefit, $C$ is the Cost, $\mathrm{n}$ is the Project life, $r$ is the Discount rate, $t$ is the Period (s), NP is the Net profit, TCI is the Total capital investment, NCF is the Negative cash flows and PCF is the Positive cash flows.

\subsection{Sensitivity Analysis}

The sensitivity of different factors, as detailed in Table 3 , were analyzed using One-Factor-At-Time (OFAT) design of experiment approach, from which the effects of different factors, such as capital/L, ROI, NPW, IRR,

\begin{tabular}{|c|c|c|c|c|}
\hline Factors & Unit & Low & Mid & High \\
\hline $\begin{array}{l}\text { Sugarcane } \\
\text { Price }\end{array}$ & $\# / \mathrm{kg}$ & 15 & 27 & 30 \\
\hline $\begin{array}{l}\text { Minimum } \\
\text { Wage }\end{array}$ & $\#$ /month & 18,000 & 20,000 & 25,000 \\
\hline Tax Rate & $\begin{array}{l}\% \text { per } \\
\text { year }\end{array}$ & 10 & 20 & 30 \\
\hline $\begin{array}{l}\text { Government } \\
\text { Subsidy }\end{array}$ & $\begin{array}{l}\% \text { per } \\
\text { year }\end{array}$ & 0 & 20 & 40 \\
\hline Exchange-rate & $\# / \$$ & 199 & 300 & 400 \\
\hline
\end{tabular}
$\mathrm{PBP}, \mathrm{B} / \mathrm{C}$ and selling price for bioethanol production in Nigeria, were examined.

Table 3: Factors examined

\section{RESULTS AND DISCUSSION}

\subsection{Profitability Analysis of the Plant}

The initial investment analysis carried out showed that if the (Bioethanol) product sells for $0.64 \$ / \mathrm{L}$ at exchange rate of $360 \mathrm{~N} / \$$ and tax rate of $20 \%$ per annum, the price is similar to that obtained by [17] at $0.64 \$ / \mathrm{L}$ in South Africa. The revenue for product sold at $0.64 \$ / \mathrm{L}$ will be $\$ 94.8$ million per annum and the gross income will be $\$ 5.37$ million per annum, resulting in a net profit of $\$ 4.29$ million per annum, with $8.40 \%$ return on investment, as reported in Table 4.

This confirms that the project is feasible and profitable, since the net present worth is positive, the internal rate of return is positive and greater than interest rate, and there is a short payback period.

The production cost estimated for fuel grade ethanol from sugarcane in Nigeria is higher than the values reported by major producers in countries such as Thailand/Vietnam (0.34 to 0.40 US $\$ / \mathrm{L})$ and Brazil/Tanzania (0.45 to 0.47 US $\$ /$ litre) $[18,19,20]$. This high cost of production was found to be as a result of the high cost (national average farm-gate price of $27.96 \mathrm{~N} / \mathrm{kg}$ ) of sugarcane in Nigeria. In Nigeria, high cost of sugarcane can be addressed through the use of motivation in form of subsidy provision for sugarcane farmers' inputs, and construction of dams.

\section{Table 4: Project Profitability Analysis}

\begin{tabular}{lcccc}
\hline Description & Code & & Unit & Amount \\
\hline Subsidy & Sub & & $\%$ & 0 \\
Cost Price & CoPv & \$/L(A/L) & $0.61(218.20)$ \\
Sale Price & SPv & \$/L(A/L) & $0.64(231.30)$ \\
Exchange Rate & $\mathrm{X}$ & $\mathrm{N} / \$$ & 360 \\
Revenue & $\mathrm{R}$ & $\mathrm{M} \$$ & 94.8 \\
Gross Income & $\mathrm{GI}$ & $\mathrm{M} \$$ & 5.37 \\
Tax Rate & $\mathrm{TR}$ & - & 0.2 \\
Net Profit & $\mathrm{NP}$ & $\mathrm{M} \$$ & 4.29 \\
Return on Investment & $\mathrm{ROI}$ & $\%$ & 8.40 \\
Net Present Worth @ 0 \% & $\mathrm{NNPW}$ & $\mathrm{M} \$$ & 160.00 \\
Net Present Worth @10 \% & $\mathrm{NPW}$ & $\mathrm{M} \$$ & 20.90 \\
Internal Rate of Return & $\mathrm{IRR}$ & $\%$ & 11.51 \\
B/C Ratio @ 0 \% & $\mathrm{NBC}$ & - & 4.09 \\
B/C Ratio @ 10 \% & $\mathrm{DBC}$ & - & 1.46 \\
Payback Period @ 0 \% & $\mathrm{PBP}$ & $\mathrm{Yr}$ & 5.96 \\
Payback Period @ 10 \% & DPBP & $\mathrm{Yr}$ & 9.64 \\
\hline
\end{tabular}

\subsection{Sensitivity Analysis}

3.2.1 Effect of Change in Price of Sugarcane Farm gate price in Nigeria Farms

The result in Table 5 shows that increase in farm-gate price of the sugarcane, at a variable selling price of Bioethanol, results to an increase in ROI, NPW, IRR, B/C and a decrease in PBP and cost of production/ manufacturing. Hence, in this study, the investment criteria are highly sensitive to change in the price of sugarcane.

Table 5: Effect(s) of Change in Price of Sugarcane

\begin{tabular}{lcrrr}
\hline Code & Unit & \multicolumn{3}{c}{ Selling Price } \\
\cline { 2 - 5 } & N/kg & 15 & 27 & 30 \\
\hline CoPv & \$/L & 0.49 & 0.61 & 0.63 \\
SPv & \$/L & 0.52 & 0.64 & 0.67 \\
R & M\$ & 77.38 & 94.85 & 99.21 \\
GI & M\$ & 4.38 & 5.37 & 5.62 \\
NP & M\$ & 3.50 & 4.29 & 4.49 \\
ROI & $\%$ & 6.85 & 8.40 & 8.78 \\
NPW & M & 15.01 & 20.94 & 22.43 \\
IRR & $\%$ & 11.20 & 11.51 & 11.58 \\
DBC & - & 1.33 & 1.46 & 1.50 \\
DPBP & Yrs & 11.43 & 9.64 & 9.31 \\
\hline
\end{tabular}




\subsubsection{Effect of Change in Tax Rate in Nigeria}

The sensitivity analysis for tax rate in Nigeria, shown in Table 6, shows that as the tax rate increased from $10 \%$ to $30 \%$, at constant cost and selling price, the net profit decreased from $\$ 4.83$ to 3.76 million per annum and ROI decreased from 9.45 to $7.35 \%$. NPW, IRR and benefit-cost also decreased, while payback period increased.

Hence, it can be deduced that change in tax rate significantly affects the net profit, ROI and payback period. This is in agreement with the report of [17] and [21] that bioethanol fuel need state intervention through its exemption of the payment of fuel taxes.

\subsubsection{Effect of Change in Minimum Wages in Nigeria}

Table 7 shows that increase in the minimum wage (in a range of 18 to 25 thousand Naira/month), at a fixed profit rate/selling price, does not have a significant effect on NPW, ROI, benefit-cost ratio, payback period, selling and cost price(s).

Table 6: Effects of Change in Tax Rate on Bioethanol Production

\begin{tabular}{lcccc}
\hline \multirow{2}{*}{ Code } & \multirow{2}{*}{ Unit } & \multicolumn{3}{c}{ Change in Tax Rate } \\
\cline { 3 - 5 } & & $10 \%$ & $20 \%$ & $30 \%$ \\
\hline CoPv & \$L & 0.61 & 0.61 & 0.61 \\
SPv & \$/L & 0.64 & 0.64 & 0.64 \\
R & M\$ & 94.85 & 94.85 & 94.85 \\
GI & M\$ & 5.37 & 5.37 & 5.37 \\
NP & M\$ & 4.83 & 4.29 & 3.76 \\
ROI & $\%$ & 9.45 & 8.40 & 7.35 \\
NPW & M\$ & 26.15 & 20.94 & 15.74 \\
IRR & $\%$ & 11.69 & 11.51 & 11.28 \\
DBC & - & 1.58 & 1.46 & 1.35 \\
DPBP & Yr & 8.80 & 9.64 & 10.81 \\
\hline
\end{tabular}

Table 7: Effect of Change in Minimum Wage in Nigeria (at a fixed profit/selling price)

\begin{tabular}{|c|c|c|c|c|c|c|c|}
\hline \multirow[t]{2}{*}{ Code } & \multirow[t]{2}{*}{ Unit } & \multicolumn{3}{|c|}{ Wage at Fixed Profit } & \multicolumn{3}{|c|}{ Wage at Fixed Selling Price } \\
\hline & & 18000 & 20000 & 25000 & 18000 & 20000 & 25000 \\
\hline $\mathrm{CoPv}$ & \$/L & 0.61 & 0.61 & 0.61 & 0.61 & 0.61 & 0.61 \\
\hline SPv & $\$ / L$ & 0.64 & 0.64 & 0.64 & 0.64 & 0.64 & 0.64 \\
\hline $\mathrm{R}$ & $\mathrm{M} \$$ & 94.85 & 94.86 & 94.91 & 94.48 & 94.48 & 94.48 \\
\hline GI & $\mathrm{M} \$$ & 5.37 & 5.37 & 5.37 & 5.00 & 4.98 & 4.94 \\
\hline NP & $\mathrm{M} \$$ & 4.29 & 4.30 & 4.30 & 4.00 & 3.98 & 3.95 \\
\hline ROI & $\%$ & 8.40 & 8.40 & 8.40 & 7.82 & 7.79 & 7.72 \\
\hline NPW & M\$ & 20.94 & 20.95 & 20.97 & 18.72 & 18.62 & 18.36 \\
\hline IRR & $\%$ & 11.51 & 11.51 & 11.51 & 11.40 & 11.39 & 11.38 \\
\hline DBC & - & 1.46 & 1.46 & 1.46 & 1.41 & 1.41 & 1.41 \\
\hline DPBP & Yr & 9.64 & 9.64 & 9.64 & 10.20 & 10.23 & 10.31 \\
\hline
\end{tabular}

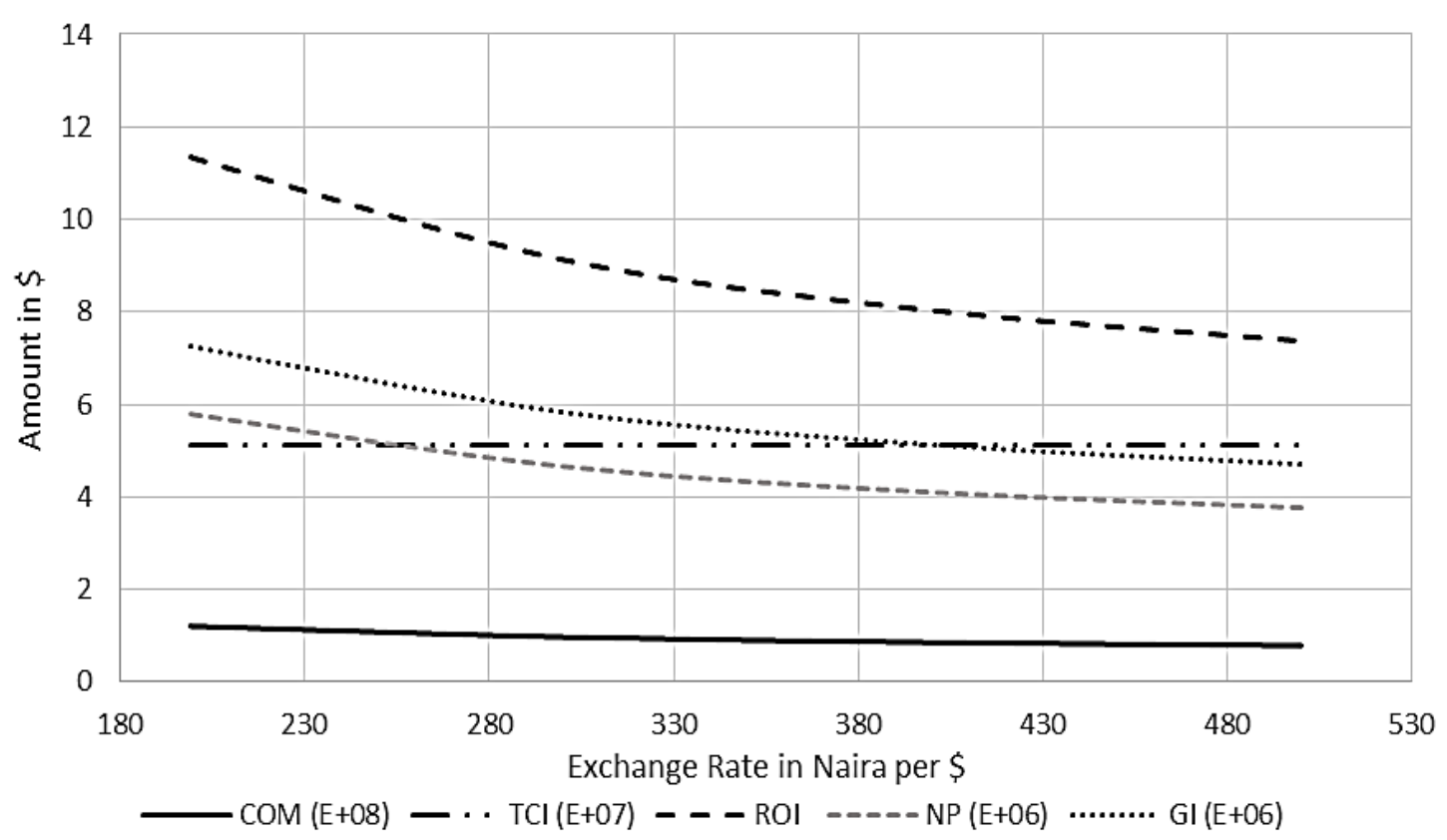

Figure 3: Effect of Rise in Dollar-Naira Exchange Rate 


\subsubsection{Effect of Government Subsidy on Bioethanol Fuel in Nigeria}

Analysis shows that increase in the rate of subsidy by the Government, from $0 \%$ to $40 \%$, would not have a significant effect on the investment criteria (values). Nevertheless, Table 8 shows that even at $0 \%$ subsidy, the project is profitable. The subsidy rate(s) of $0 \%, 20$ $\%$ and $40 \%$ infer bioethanol selling price of $0.64,0.51$ and $0.39 \$ / \mathrm{L}$, respectively. Thus an increase in the subsidy rate from $0 \%$ to $20 \%$ would decrease the selling price of the bioethanol from 0.64 to $0.51 \$ / \mathrm{L}$, even though the cost price is unchanged/unaffected at $0.61 \$ / \mathrm{L}$.

Table 8: Effect of Government Subsidy on the investment criteria (value(s)) of the proposed plant

\begin{tabular}{lcccc}
\hline Code & Unit & \multicolumn{3}{c}{ Change in Subsidy } \\
\cline { 3 - 5 } & & $0 \%$ & $20 \%$ & $40 \%$ \\
\hline CoPv & \$L & 0.61 & 0.61 & 0.61 \\
SPv & $\$ / L$ & 0.64 & 0.51 & 0.39 \\
R & M\$ & 94.85 & 94.85 & 94.85 \\
GI & M\$ & 5.37 & 5.37 & 5.37 \\
NP & M\$ & 4.29 & 4.29 & 4.29 \\
ROI & $\%$ & 8.40 & 8.40 & 8.40 \\
NPW & M\$ & 20.94 & 20.94 & 20.94 \\
IRR & $\%$ & 11.51 & 11.51 & 11.51 \\
DBC & - & 1.46 & 1.46 & 1.46 \\
DPBP & Yrs & 9.64 & 9.64 & 9.64 \\
\hline
\end{tabular}

At the selling price of $0.64 \$ / \mathrm{L}$, the bioethanol price is higher than the reported value(s) of $0.43 \$ / L(0.3$ EURO/L) [22] and 0.48 \$/L [23], but lower than the $0.67 \$ / \mathrm{L}$ reported [24]. Therefore, in order to encourage the use of Bioethanol, there is a need for the Nigeria government to subsidize Bioethanol sales and production; and thus contribute to a sustainable environment and economy.

\subsubsection{Effect of Rise in Dollar-Naira Exchange Rate}

As a result of the changing Dollar-Naira exchange rate, it is paramount to analyse the effect of exchange rate on the proposed plant. Figure 3 shows the effect(s) of increase in the Dollar-Naira exchange rate on COM, TCI, ROI, NP, GI, cost ( $\mathrm{CoPv}$ ) and selling (SPv) price. The figure indicates that as the exchange rate of Dollar to Naira increases, the COM decreases with a standard deviation of $\$ 0.19$, TCI remains constant with zero standard deviation, and there is significant decrease in ROI, NP and GI with standard deviation(s) of $\$ 1.83$, \$ 0.94 and $\$ 1.17$ respectively.
This study confirms that increase in exchange rate significantly affects the economic viability of bioethanol production in Nigeria.

\section{CONCLUSION}

The techno-economic analysis of the proposed combined cellulosic-sugar based bioethanol plant shows ROI of $8.40 \%$, NPW at $0 \%$ of $\$ 160$ million, NPW at $10 \%$ of $\$ 20.90$ million, IRR of $11.51 \%$, B/C at $0 \%$ of $4.09, \mathrm{~B} / \mathrm{C}$ at $10 \%$ of $1.46, \mathrm{PBP}$ at $0 \%$ of 5.96 years and PBP at $10 \%$ of 9.64 years. Thus, this study shows that a plant producing 148 million liters of fuel grade bioethanol from 402 metric tonnes per annum of crushed sugarcane would be economically feasible in Nigeria, based on the conditions adopted for this study. Sensitivity analysis showed that change in the price of sugarcane had significant effect on the NP, ROI, and PBP, while change(s) in minimum wage and Government subsidy do not seem to have significant effect on the investment criteria. Sensitivity analysis also showed that as the Dollar-Naira exchange rate increased significantly, the viability of the proposed plant decreased significantly. The study highlights that for an estimated selling price (range) of 0.39 to 0.64 $\$ / \mathrm{L}$ of Bioethanol in Nigeria, sugarcane cost should be as low as $15 \mathrm{~N} / \mathrm{kg}$, Government subsidy should be in the range of 20 to $40 \%$, and there should be a moderate tax rate of $20 \%$ (maximum) on the Bioethanol being sold as fuel.

\section{REFERENCES}

[1] ECN, "Renewable Energy Master Plan," [Online]. Available: http://www.energy.gov.ng. [Accessed 12/08/2012].

[2] N. Q. Diep, "Evaluation of the Potentials for Development of Ethanol Production from Rice Straw in Vietnam," Vietnam, 2014.

[3] D. Lashof and D. Ahuja, "Relative contribution of greenhouse gases emissions to Global warming," Nature, 344, 529-531, 1990.

[4] R. Pachauri and A. Reisinger, "IPCC Climate Change 2007: Synthesis Report," in Intergovernmental Panel on Climate Change (IPCC) 4th Assessment, Cambridge , United Kingdom, 2007.

[5] A. Hansen, Q. Zhang and P. Lyne, "Ethanol-diesel fuel blends-a review," Bio-resource Technology, 96, 277-85, 2005.

[6] I. Misau, I. Bugaje, J. Mohammed, I. Mohammed and B. Diyaudeen, "Production of Bioethanol from Sugarcane: A Pilot Scale Study in Nigeria," 
Journal of Engineering Research and Applications, 2(4), 1142-1151, 2012.

[7] M. Balat, "An overview of biofuels and policies in the European Union," Energy Source-B Energy Economic Planning, 2, 167-181, 2007.

[8] "Why are oil prices falling here," 29 April. [Online]. Available: http://www.ibtimes.com/why-are-oil-pricesfalling-here-are-four-reasons-crude-pricescontinue-trend-lower-1848742, 2015.

[9] "Oil Price Chart," [Online]. Available: https://oilprice.com/oil-price-charts. [Accessed 5/06/2018].

[10] S. Sukapong, "Feasibility Study of Small Scale Ethanol Production from Cassava for Gasohol," Mahidol University Publications, MahidolThailand, 2006.

[11] T. Oyegoke and F. N. Dabai, "Techno-economic Feasibility Study of Bioethanol Production from a Combined Cellulose and Sugar Based Feedstock: 1-Modelling, Simulation and Cost Evaluation," Nigeria Journal of Technology, 37(4), (In Press), 2018.

[12] NASS, "Collaborative Survey on National Agricultural Sample Survey 2010/2011," National Bureau of Statistics and Federal Ministry of Agriculture and Rural Development, Abuja, 2012.

[13] R. Sinnott, Coulson \& Richardson's Chemical Engineering: Chemical Engineering Design, Fourth Edition, Vol.6, Jordan Hill, Oxford OX2 8DP: Elsevier Butterworth-Heinemann, Linacre House, p.245-275, 2005.

[14] T. Richard, C. Richard, B. Wallace, A. Joseph and B. Debangsu, Analysis, Synthesis and Design of Chemical Processes, Fourth Edition, New Jersey: Prentice Hall International, Pearson Education, Inc., 2012.
[15] T. Gavin and S. Ray, Chemical Engineering Design: Principles, Practice and Economic of Plant and Process Design, London, UK: Butterworth-Heinemann, p.297-392, 2008.

[16] K. Ajit and D. Pearce, Cost-benefit analysis: Theory and practice, New York: Dublin, 1973.

[17] K. Marcel, "An Economic Assessment of Bioethanol Production from Sugarcane: Case Study of South Africa," Economic Research Southern Africa, 2016.

[18] T. Molony and J. Smith, "Biofuels, food security, and Africa," African Affairs, 109(436), 489-498, 2010.

[19] C. Zhang, W. Han, X. Jing, G.Pu and C. Wang, "Life cycle economic analysis of fuel ethanol derived from cassava in southwest China," Renewable Sustainable Energy Review, 7, 353-366, 2003.

[20] J. A. Quintero, C. A. Cardona, E. Felix, J. Moncada and J. C. Higuita, "Techno-economic analysis of fuel ethanol production from cassava in Africa: The case of Tanzania," African Journal of Biotechnology, 14(45), 3082-3092, 2015.

[21] F. Braude, "Towards a SADC Fuel Ethanol Market from Sugarcane: Regulatory Constraint and Model Regional Sectoral Integration," Emet Consulting, Wolfe Braude, 2014.

[22] "Cellulosic Ethanol Proesa," [Online]. Available: http://www.biochemtex.com/proesa. [Accessed 29/10/2015].

[23] I.D.o.W.R.E.D. CON00532, "Ethanol Impact Assessment for the State of Idaho," BBI Internationals-Boise, 2004.

[24] MBG, Proposal Report on Production of Bioethanol from Sugarcane Bagasse, Australian Renewable Energy Agency, 2013. 